\title{
Characterization and Designing Integral Sliding Mode Controller for 2-Link Robot System with Coulomb Friction
}

\author{
Dena Hameed Tu'ma ${ }^{1}$, Ahmed Khalaf Hamoudi ${ }^{2 *}$
}

\section{Authors affiliations: \\ 1) Department of Control \& System Engineering, University of Technology, Baghdad, Iraq. dena94hameed@gmail.com}

$\left.2^{*}\right)$ Department of Control \& System Engineering, University of Technology, Baghdad, Iraq. 60155@uotechnology.edu.iq

\section{Paper History:}

Received: $2^{\text {nd }}$ Oct. $20 \mathrm{xx}$

Revised: $9^{\text {th }}$ Dec. 20xx

Accepted: $30^{\text {th }}$ Jan. 2 0xx

\begin{abstract}
The indemnification of uncertainty and disturbance which is added to non-linear systems by an Integral Sliding Mode Controller (ISMC) design. the key target of this paper is designing a sturdy controller to observe the performance of a 2-link robot. The nonlinearity in mechanical systems is a shared issue that the researchers are facing in formulating control systems for it. The best solution to this problem is a design Sliding Mode Controller (SMC) for controlling a nonlinear system. In the current paper, 2-link robot is studied which suffering from disturbances and parameter uncertainty and coulomb friction as additional to friction inertia of the system for each link. firstly, Classical Sliding Mode Controller (CSMC) is designed and then Integral Sliding Mode Controller (ISMC). As known, CSMC includes two phases: reaching phase and sliding phase. SMC is suffering from the known phenomenon as "chattering" which is supposed as a critical case and unsuitable characteristic. chattering is described as a curvy movement span the switching surface. In the current study, the chattering is attenuated by employing a saturation function alternative of a sign function. Although SMC can be considered as a good way of controlling nonlinear systems. Where it continues to suffer from the long settling time as undesired features. ISMC is a good method can be employed for reducing the settling time and controlling a nonlinear system. ISMC is easy, robust execution and supposes as an active and strong technique. The most significant advantage in ISMC designing, the reaching phase is canceled that considered a major part of designing classical SMC. The 2 link Robot system was used for proving the performance of CSMC and ISMC algorithms. The outcomes received from the simulations utilizing the ISMC and CSMC which fulfilled asymptotic stability for the system. In comparative between CSMC and ISMC. ISMC is better than CSMC in the good performance of tracking the desired position with less time. Finally, MATLAB2019a software package has relied upon this work.
\end{abstract}

Keywords: Chattering, Classical Sliding Mode Controller, Integral Sliding Mode Controller, Signum Function, Saturation Function.

$$
\begin{aligned}
& \text { توصيف وتصميم وحدة تحكم وضع الانزلاق المتكاملة لنظام روبوت ثنائي الوصلة مع } \\
& \text { احتكلك كولوم } \\
& \text { دينا حميد طعمة، احمد خلف حمودي }
\end{aligned}
$$

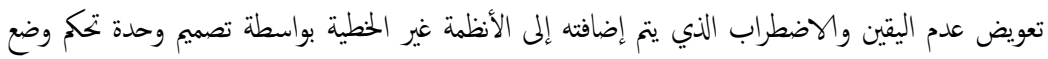

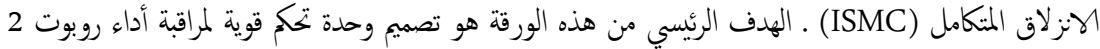

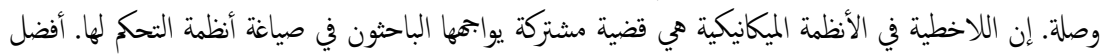

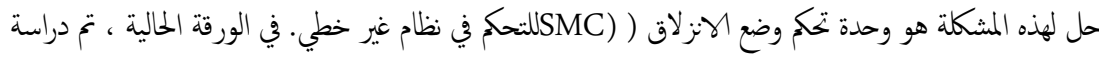

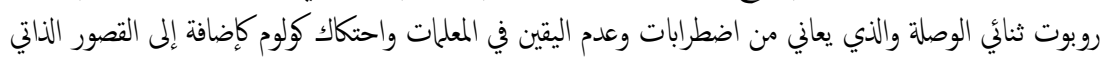




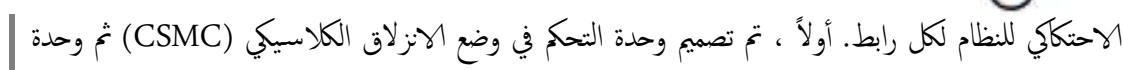

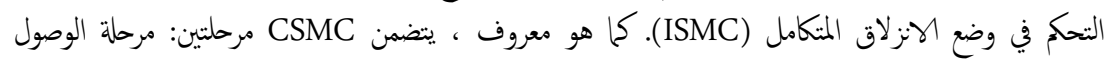

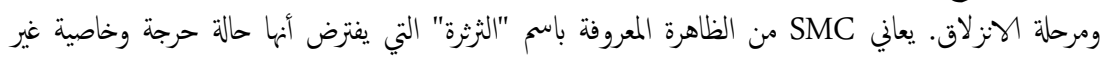

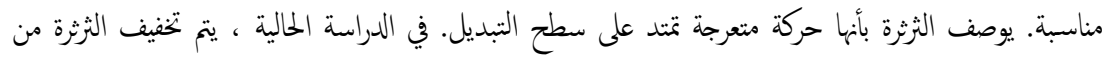

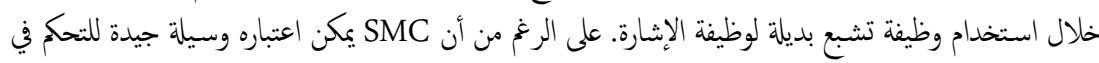

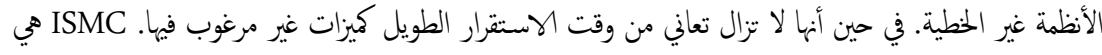

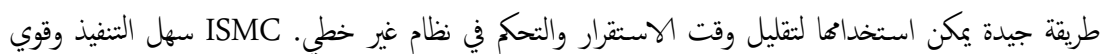

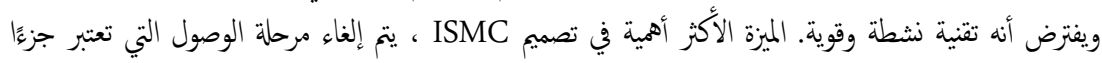

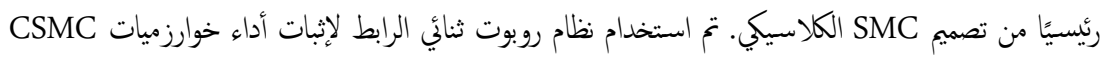

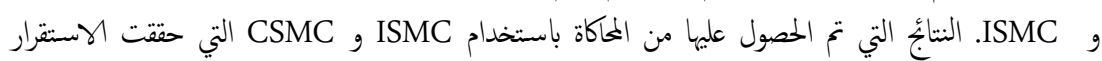

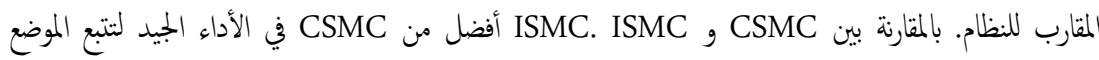

$$
\begin{aligned}
& \text { المطلوب بوقت أقل. وأخيرًا ، اعتمدت حزمة برامج MATLAB2019a على هذا العمل. }
\end{aligned}
$$

\section{Introduction}

SMC had acquired raising attention from research workers within the last several years. The basic theory of SMC is founded in research works, for example, ISMC as one of the major methods for designing strong control actions for non-linear systems. SMC has lots of features like robustness, fast response, invariable to system uncertainty and indemnificationcapacity to the outer disturbance. Simultaneously, these are few imperfections related to it. As an example, ruling chattering and reaching phase [1]. The SMC method includes two phases. First, a sliding surface, which have to be owned by the trajectories, is designed with matching to some performance standard. after that, a discontinuous control is formulated to oblige the system state for reaching the sliding surface where a sliding happens on this "manifold". When a sliding mode is achieved, the system shows forcefulness properties concerning parameter uncertainty and external disturbances [2]. where, the system dynamics are ruled by sliding surface dynamics granting perfectly robustness to the system [3]. However, this controller utilized widely but, pure sliding mode controllers have the following drawbacks. First, the zigzag problem; which can be caused by the high-frequency oscillation in the controller's output. Secondly, sensitivity; this controller is very sensitive to the noise when the input signals very approaching from the zero. Last, nonlinear equivalent dynamic formation; that this matter is very essential to have an efficient performance and it is hard to computation because it is based on the nonlinear dynamic equation. We were first submitted ISMC, which is similar to the SMC whereas it is insensitive to external disturbance and parameter variations. In the ISMC, the control law includes two main branches. The first branch is the nominal control that is considered accountable about the action of the nominal system. The second branch, the discontinuous control which is utilized to refuse the outer disturbances and variation parameters [5],[4] and[7]. The 2 link Robot system with Coulomb friction is utilized for checking CSMC and ISMC.
The outcomes found from the simulation results illustrate the features of utilizing ISMC in compared with CSMC which are describes a good performance for the two assumed methods. This study is organized as follows. Section 2 introduces the system model. Then Section 3 designs the controller, which is included ISMC and CSMC. whereas the simulations outcomes are offered in Section 4. Section 5 gives the discussion of outcomes. in Section 6, work conclusions are illustrated.

\section{Two Link Robot}

Robotic manipulators are collected from chains of links and joints. Robotic manipulators can execute several actions in many fields. robotic systems can be employed in disadvantageous surroundings for keeping safety and industrial environments to manufacture machinery and automation. Subsequently, in the latest years, increasing attention is formed concerning the control of robotic systems $[6,20]$. In this paper, the 2-link Robot system is used for checking the two methods of the controller as follows CSMC and ISMC. the system of a 2-link robot can be described as nonlinear because the perturbations term can be added to it that includes the uncertainty of the parameters, disturbance. The 2-link robot can be clarified as shown in Fig.1 below.

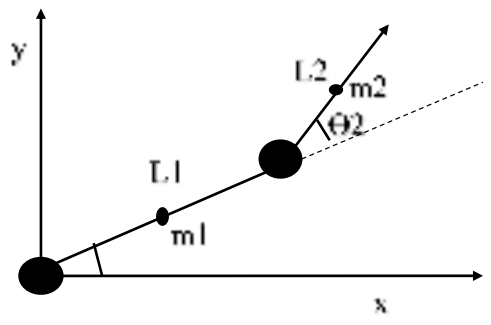

Figure (1): 2- Link Robot Arm.

The nonlinear differential equation of the 2-Link Robot that characterizes the conduct for dynamics of the system is described followed [15 and 16]: 
$\mathrm{M}(\theta) \ddot{\theta}+\mathrm{C}(\theta . \dot{\theta}) \dot{\theta}+\mathrm{G}(\theta)+\delta(\mathrm{x}, \mathrm{u})=\tau$

Where $\theta \cdot \dot{\theta} . \ddot{\theta}$ are $2 \times 1$ vectors of joint angular position, velocity and acceleration respectively, $\tau$ is a $2 \times 1$ vector of torque action, $\mathrm{M}(\theta)$ and $\mathrm{C}(\theta . \dot{\theta})$ are $2 \times 2$ matrices of inertia and Coriolis and centrifugal forces, respectively, and $\mathrm{G}(\theta)$ is a $2 \times 1$ gravity vector. $\quad \theta_{1}$ and $\theta_{2}$ are constrained. $\delta(x, u)$ perturbation term which contains parameter variation and disturbance and coulomb friction. The detailed eq. (1) can be written as follows:

$$
\begin{aligned}
& \mathrm{M}(\theta)=\left[\begin{array}{ll}
\mathrm{M}_{11} & \mathrm{M}_{12} \\
\mathrm{M}_{21} & \mathrm{M}_{22}
\end{array}\right] \\
& \mathrm{M}_{11}=\left(\mathrm{m}_{1}+\mathrm{m}_{2}\right) \mathrm{L}_{1}^{2}+\mathrm{m}_{2} \mathrm{~L}_{2}^{2}+2 \mathrm{~m}_{2} \mathrm{~L}_{1} \mathrm{~L}_{2} \operatorname{Cos}\left(\theta_{2}\right) \\
& \mathrm{M}_{12}=\mathrm{M}_{21}=\mathrm{m}_{2} \mathrm{~L}_{2}^{2}+2 \mathrm{~m}_{2} \mathrm{~L}_{1} \mathrm{~L}_{2} \operatorname{Cos}\left(\theta_{2}\right) \\
& \mathrm{M}_{22}=\mathrm{m}_{2} \mathrm{~L}_{2}^{2}
\end{aligned}
$$

Where $\boldsymbol{\tau}_{\mathbf{1}}, \boldsymbol{\tau}_{\mathbf{2}}$ torque action for each link of the robot. $\mathbf{m}_{\mathbf{2}}$ and $\mathbf{m}_{\mathbf{1}}$ are represented the masses for link2 and link 1 respectively. $\mathbf{L}_{\mathbf{2}}$ and $\mathbf{L}_{\mathbf{1}}$ are represented the length for link 2 and link 1 . The actual positions are represented in $\boldsymbol{\theta}_{\mathbf{1}}$ and $\boldsymbol{\theta}_{\mathbf{2}}$.

$\boldsymbol{\theta}_{\mathbf{1}}=\mathbf{x}_{\mathbf{1}}+\boldsymbol{\theta}_{\mathbf{1}} \mathbf{d}$
$\theta_{2}=\mathrm{x}_{2}+\theta_{2} \mathrm{~d}$

$\theta_{1}$ d. $\theta_{2}$ d are the desired angles for joint 1 and joint 2 .

The Robot model can be rewritten in state space equations form to apply SMC as in the below:

$\dot{\mathrm{X}}_{1}=\mathrm{X}_{2}$

$\dot{\mathrm{X}}_{2}=-\mathrm{M}(\theta)^{-1}[\mathrm{C}(\theta . \dot{\theta}) \dot{\dot{\theta}}+\mathrm{G}(\theta)+\tau+\delta(\mathrm{x}, \mathrm{u})]^{(3)}$

The eq. (3) can be repeated:

$$
\begin{aligned}
& \dot{\mathrm{X}}_{1}=\mathrm{X}_{2} \\
& \dot{\mathrm{X}}_{2}=\mathrm{F}+\mathrm{wu}+\delta
\end{aligned}
$$

Where $\mathrm{w}$ represent constant value and other abbreviations in the equation is written with details below:

$$
\begin{aligned}
& X 1=\left[\begin{array}{l}
\mathrm{X}_{1} \\
\mathrm{X}_{2}
\end{array}\right], \mathrm{X} 2=\left[\begin{array}{l}
\mathrm{X}_{3} \\
\mathrm{X}_{4}
\end{array}\right] \\
& \mathrm{F}=\left[\begin{array}{l}
\mathrm{F}_{1} \\
\mathrm{~F}_{2}
\end{array}\right]=-\mathrm{M}(\theta)^{-1}[\mathrm{C}(\theta \cdot \dot{\theta}) \dot{\theta}+\mathrm{G}(\theta)]
\end{aligned}
$$

$$
\mathrm{u}=\left[\begin{array}{l}
u_{1} \\
u_{2}
\end{array}\right]=-\mathrm{M}(\theta)^{-1} \tau
$$

Where the uncertainty parameters $\Delta \mathrm{F}=20 \% \mathrm{~F}$ and $\Delta \mathrm{w}=10 \% \mathrm{w}$

$$
\begin{gathered}
\delta(\mathrm{x} . \mathrm{u})=\left[\begin{array}{c}
\delta_{1}\left(\mathrm{x}_{\mathrm{u}} \mathrm{u}_{1}\right) \\
\delta_{2}\left(\mathrm{x} \cdot \mathrm{u}_{2}\right)
\end{array}\right]=\Delta \mathrm{F}+\Delta \mathrm{wu}+\mathrm{Fc}+ \\
\mathrm{D}(\theta \cdot \dot{\theta}) . \ldots \ldots(8)
\end{gathered}
$$

Where $\mathrm{D}(\theta \cdot \dot{\theta})=\left[\begin{array}{l}(\mathrm{w}+\Delta \mathrm{w}) \mathrm{d}_{1} \\ (\mathrm{w}+\Delta \mathrm{w}) \mathrm{d}_{2}\end{array}\right]$ is the disturbances function, $\mathrm{Fc}=\left[\begin{array}{l}\mathrm{Fc} 1 \\ \mathrm{Fc} 2\end{array}\right]$ is coulomb friction for the two joints.

The set of differential equations distinguishing the action of the system are:

$$
\begin{aligned}
& \dot{x_{1}}=x_{3} \\
& \dot{x_{2}}=x_{4} \\
& \dot{x_{3}}=F_{1}+w u_{1}+\delta_{1}\left(x . u_{1}\right) \\
& \dot{x_{4}}=F_{2}+w_{2}+\delta_{2}\left(x . u_{2}\right)
\end{aligned}
$$

\section{Control Methods}

\subsection{Classical sliding mode control}

$\mathrm{SMC}$ is one of the featured control techniques because of firstly, its powerful outer disturbance refusal. secondly, insensibility performance for parameters variation when matching condition holds. from the 1950s till now, SMC has been attracting much attention both in theoretical study and application area [11 and 26]. For controlling the nonlinear systems, the ultimate challenging cases in designing a control algorithm that is to design for nonlinear systems a linear controller. This process, however, still needs some strict set up in that the controller must active near the system operating point but This way is very complicated because of presence high nonlinearity and large variations in dynamic system parameters [8]. regardless of the robustness, the SMC still suffering from a fundamentals disadvantage known as "chattering" which is described as high frequency leads to undesirable swinging which impacts the control of the actions for the system. This trouble can be reducing the performance of the system or makes it increase to instability. Two major causes of chattering have been specified: Firstly, speedy dynamics in the control loop, that were ignored in the system model, are often activated by the fast switching of sliding mode controllers. Second, digital applications in microcontrollers with constant sampling rates may be leading to chatter. The eliminating of zigzag motion in the SMC system by employing a smooth function in the control law as will be visible later when a sliding mode control is designed for 2-link robot systems [10].

The designing of CSMC consists from the following points [12, 22 and 17]:

- Designing an appropriate switching surface that grants the desired actions for the systems. 
- Building of a discontinuous control law which proposes the trajectories to the switching surface and keeps them there as long as sliding mode is provided of for all time later.

- consequently, the control issue is abstracted in specifying a sliding surface and a control law.
The state path of a system which utilizing a SMC is including two phase as shown in Fig.2: reaching phase and sliding phase [24].

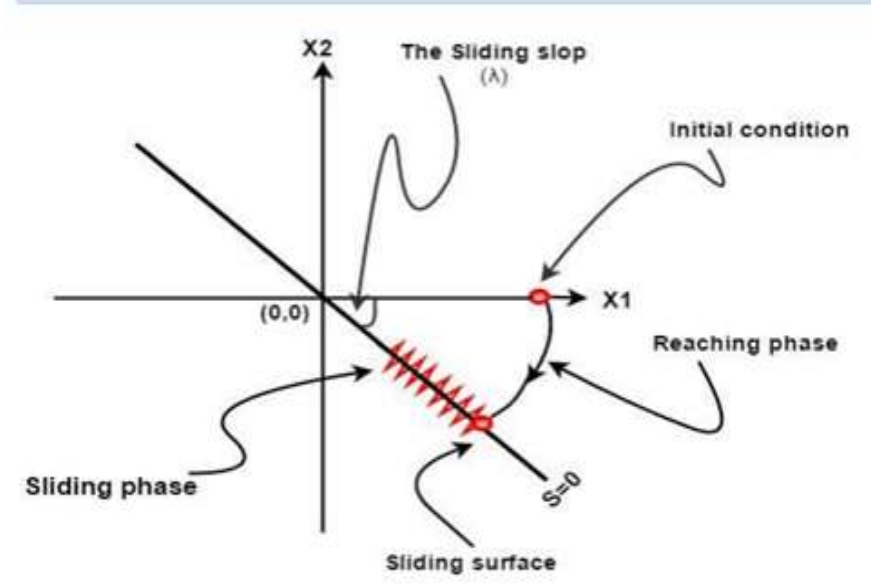

Figure (2): Phases of the SMC [21]

The design of control action for CSMC with uncertain values is describing as following equation:

$$
\mathrm{u}=\mathrm{u}_{\mathrm{dis}}=-\mathrm{k}(\mathrm{x}) \operatorname{sign}(\mathrm{s})
$$

Where,

$$
\operatorname{sign}(s)= \begin{cases}1 & \text { if } s>0 \\ -1 & \text { if } s<0 \\ \in[-1.1] & \text { if } s=0\end{cases}
$$

This equation can be modified by utilizing a saturation function for reducing the chattering in the control action [18].

$$
\mathrm{u}=\mathrm{u}_{\mathrm{dis}}=-\mathrm{k}(\mathrm{x}) \operatorname{sat}(\mathrm{s})
$$

Where the boundary layer (sat function) is defined as [13]:

$\operatorname{sat}(\mathrm{s}, \varphi)= \begin{cases}\operatorname{sign}(\mathrm{s}) & \text { if }|\mathrm{s}|>\varphi \\ \frac{\mathrm{s}}{\varphi} & \text { if }|\mathrm{s}| \leq \varphi\end{cases}$

Where the sliding surface can be written as below:

$$
\mathrm{s}=\lambda \mathrm{e}+\dot{\mathrm{e}}=0
$$

Where $\lambda=10, \mathrm{x}_{1}=\mathrm{e}$ is the error and $\mathrm{x}_{2}=\dot{\mathrm{e}}$ is the derivative of error. The sliding variable equation are phrased as:

$$
\begin{aligned}
& s_{1}=10 x_{1}+x_{3} \\
& s_{2}=10 x_{2}+x_{4}
\end{aligned}
$$

$\dot{\mathrm{s}}<0$ The proper discontinuous gain $\mathrm{k}(\mathrm{x})$ is calculated from utilizing, where

$$
\begin{aligned}
& \boldsymbol{s}=\left[\begin{array}{l}
S_{1} \\
S_{2}
\end{array}\right] \\
& \mathrm{wk}(\mathrm{x})>|\delta(x \cdot u)| \\
& \mathrm{k}(\mathrm{x})=\mathrm{k}_{0}+\frac{\Delta \mathrm{f}+D(\theta \cdot \dot{\theta})}{(w-\Delta w)}
\end{aligned}
$$

so that, $\mathrm{k}_{0}$ is a fixed value and its value is greater than zero.

$$
\mathrm{k}(\mathrm{x})=\left[\begin{array}{l}
k_{1}(x) \\
k_{2}(x)
\end{array}\right]
$$

After having found each link's gain values, which is replaced in Eq. (12), and then finding torque for each link of robot below by:

$$
\begin{aligned}
& \tau_{1}=M_{11} u_{1}+M_{12} u_{2} \\
& \tau_{2}=M_{21} u_{1}+M_{22} u_{2}
\end{aligned}
$$

\subsection{Integral sliding mode controller}

The robustness characteristic of SMC with consideration of uncertainty parameters and outer disturbances is fulfilled only after the existence of sliding mode. through the reaching phase, in whatever way, robustness property is not guaranteed. ISMC looks up to remove the reaching phase by applying sliding mode during the full response system [25]. Different from the classical design way, the movement equation order in ISMC is maintain the same arrangement of the original system instead of minimizing the input dimension for the control action. As a consequence, the system robustness is guaranteed beginning from the initial time moment. The notion of ISMC can as well be extensive to build a modern kind of perturbation estimator which solves the chattering issue without missing of validity of 
control [13]. The chattering phenomenon can be effected in the control action as shown in Fig. 3.

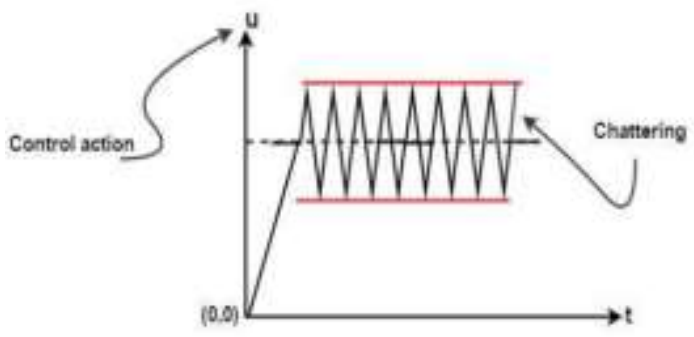

Figure (3): The Chattering in Control Action [5]

to minimize this chattering might utilize some functions like a dead zone, saturation and arc tan rather than sign function that is usually utilized in SMC [4 and 23]. ISM design that be composed of continuous nominal control and the discontinuous control [1]. with the liberty for designing a nominal control for the sliding manifold, ISMC can be combined easily with other power control techniques, like linear matrix inequality (LMI), $\mathrm{H} \infty$, and linear quadratic regulator (LQR) to treat with the unmatched uncertainties. on the other hand, ISMC contributes one more degree of freedom in selecting a suitable projection matrix to minimize the impact of the unmatched uncertainties [14]. With the close-loop system, ISMC is inserted to control the robot system performance and give desired behavior of robot motion and stability assurance, as Fig.4 below.

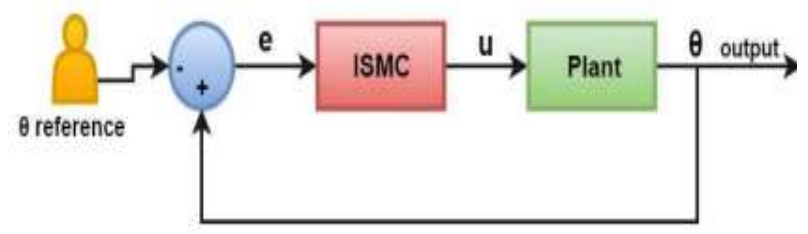

Figure (4): ISMC within closed-loop control system.

The designing steps of ISMC for any nonlinear system can be designated as below [18]:

As the first stage in ISMC design steps the sliding $\mathrm{s}(\mathrm{x})$ is known as:

$$
\begin{aligned}
& \mathrm{s}(\mathrm{x})=\mathrm{s}_{0}(\mathrm{x})+\mathrm{z} \\
& \mathrm{z}(0)=-\mathrm{s}_{0}(0) \\
& \mathrm{s}_{01}=10 \mathrm{x}_{1}+\mathrm{x}_{3} \\
& \mathrm{~s}_{02}=10 \mathrm{x}_{2}+\mathrm{x}_{4}
\end{aligned}
$$

Eq. (21) includes two sections: the first section $\mathrm{s}_{0}(\mathrm{x})$ is designed as a linear collection of the system states, like to the CSMC. second section suggests the integral term which is specified below. for applying the sliding condition $\mathrm{s} * \dot{\mathrm{s}}<0, \dot{\mathrm{s}}$ is differentiated as below:

$\dot{\mathrm{s}}=\frac{\partial \mathrm{s}_{0}}{\partial \mathrm{x}} \dot{\mathrm{x}}+\dot{\mathrm{z}}$

the derivation of the integral term can formulate as.

$\dot{z}=\frac{\partial s_{0}}{\partial x}\left(f n(x)+g n(x) u_{n}\right)$
Secondly, the control law of the ISMC is written as:

$u=u_{n}+u_{d i s}$

Where $\mathrm{u}_{\mathrm{n}}$ : nominal control which utilizes to achieve stability the nominal system dynamics with the required properties. The equation for nominal system dynamics is written without parameters uncertainty.

$\dot{x}=f n(x)+g n(x) u_{n}$

The discontinuous control $\mathrm{u}_{\mathrm{dis}}$ designed to reject the perturbation term.

$\delta(x . u)=\Delta \mathrm{f}(\mathrm{x})+\Delta \mathrm{g}(\mathrm{x}) \mathrm{u}+\mathrm{d}(\mathrm{x} . \mathrm{t})$

The perturbation term associate with parameter uncertainty, external disturbances, nonsmooth nonlinearities, and unmodeled dynamics. where the discontinuous controller as mentioned in eq. (10):

$\mathrm{u}_{\mathrm{dis}}=-\mathrm{k}(\mathrm{x}) \operatorname{sign}(\mathrm{s})$

$\mathrm{u}=\mathrm{u}_{\mathrm{n}}-\mathrm{k}(\mathrm{x}) \operatorname{sign}(\mathrm{s})$

$\mathrm{k}(\mathrm{x})=\mathrm{k}_{0}+\left|\frac{\frac{\partial \mathrm{s}_{0}}{\partial \mathrm{x}} \partial(\mathrm{x} . \mathrm{u})}{\frac{\partial \mathrm{s}_{0}}{\partial \mathrm{x}} \operatorname{gn}(\mathrm{x})}\right|, \mathrm{k}_{0}>0$

Where $\mathrm{k}_{0}$ (discontinuous gain) is positive constant. In the design of the ISMC for 2 -link Robot, the sliding surface, and control will be described as in eq. (21), eq. (22) and eq. (25):

$\mathrm{s}(\mathrm{x})=\mathrm{s}_{0}(\mathrm{x})+\mathrm{z} . \quad \mathrm{z}(0)=-\mathrm{s}_{0}(0)$

$\dot{\mathrm{s}}=\frac{\partial \mathrm{s}_{0}}{\partial \mathrm{x}} \dot{\mathrm{x}}+\dot{\mathrm{z}}$. and the integral term in Eq. (25) can be written for the 2 -link Robot system as below:

$$
\begin{aligned}
& \dot{\mathrm{z}_{1}}=C_{1} \mathrm{x}_{1}+\mathrm{C}_{2} \mathrm{x}_{3}-\mathrm{F}_{1} \\
& \dot{\mathrm{z}_{2}}=C_{1} \mathrm{x}_{2}+\mathrm{C}_{2} \mathrm{x}_{4}-\mathrm{F}_{2}
\end{aligned}
$$

For critical damped characteristic c1, c2 $>0$.

Finally, the eq. (30) can be reformulate by utilizing saturation function for minimizing chattering as below:

$$
\mathrm{u}=\mathrm{u}_{\mathrm{n}}-\mathrm{k}(\mathrm{x}) \operatorname{sat}(\mathrm{s})
$$

For 2 -link Robot system, the nominal control, and discontinuous gain can be written as below:

$$
\begin{aligned}
& \mathrm{u}_{\mathrm{n}}=\frac{1}{\mathrm{w}}[\ddot{\mathrm{e}}-\mathrm{F}] \\
& \text { let } \ddot{e}_{1}=-\mathrm{C}_{1} \mathrm{x}_{1}-\mathrm{C}_{2} \mathrm{x}_{3} \\
& \text {. } \ddot{e}_{2}=-\mathrm{C}_{1} \mathrm{x}_{2}-\mathrm{C}_{2} \mathrm{x}_{4}
\end{aligned}
$$

c1 and c2 $>0$, chosen upon the system performance.

$\mathrm{k}(\mathrm{x})=\mathrm{k}_{0}+\frac{\Delta \mathrm{f}+D(\theta \cdot \dot{\theta})}{(w-\Delta w)}$ 
so that, $\mathrm{k}_{0}$ is a fixed value and its value is greater than zero.

$k(x)=\left[\begin{array}{l}k_{1}(x) \\ k_{2}(x)\end{array}\right]$

after finding the values of Eq. (36) can be substitute in Eq. (19) and Eq. (20) to find the torques for each link.

\section{The Simulation Results}

For proving the proposing controllers' algorithms, parameters can be utilized in the simulation program as below.

Table (1): Simulation Parameters of 2-link Robot.

\begin{tabular}{|l|l|l|}
\hline parameter & Description & Value (unit) \\
\hline $\mathrm{L}_{1}$ & $\begin{array}{l}\text { The length of } \\
\text { link 1. }\end{array}$ & $0.12(\mathrm{~m})$ \\
\hline $\mathrm{L}_{2}$ & $\begin{array}{l}\text { The length of } \\
\text { link 2. }\end{array}$ & $0.08(\mathrm{~m})$ \\
\hline $\mathrm{m}_{1}$ & $\begin{array}{l}\text { The mass of link } \\
1\end{array}$ & $0.01996(\mathrm{~kg})$ \\
\hline $\mathrm{m}_{2}$ & $\begin{array}{l}\text { The mass of link } \\
2\end{array}$ & $0.0076(\mathrm{~kg})$ \\
\hline$\theta_{1}$ desired & $\begin{array}{l}\text { Theta desired of } \\
\text { link 1 }\end{array}$ & $\begin{array}{l}\pi / 2[1-\mathrm{e}(-5 \mathrm{t})(5 \mathrm{t}+1)] \\
(\mathrm{rad} .)\end{array}$ \\
\hline$\theta_{2}$ desired & $\begin{array}{l}\text { Theta desired of } \\
\text { link 2 }\end{array}$ & $\begin{array}{l}\pi / 2[1-\mathrm{e}(-5 \mathrm{t})(5 \mathrm{t}+1)] \\
(\mathrm{rad} .)\end{array}$ \\
\hline $\mathrm{d}_{1}$ & $\begin{array}{l}\text { Disturbance of } \\
\text { link 1 }\end{array}$ & $0.01 \sin (\mathrm{t})(\mathrm{N} . \mathrm{m})$. \\
\hline $\mathrm{d}_{2}$ & $\begin{array}{l}\text { Disturbance of } \\
\text { link 2 }\end{array}$ & $0.01 \sin (\mathrm{t})(\mathrm{N} . \mathrm{m})$. \\
\hline $\mathrm{F}_{\mathrm{c} 1}$ & $\begin{array}{l}\text { Coulomb } \\
\text { frictions of link } \\
1\end{array}$ & $\begin{array}{l}\text { Coulomb } \\
\text { frictions of link } \\
2\end{array}$ \\
\hline$\Phi_{1}, \Phi_{2}$ & $\begin{array}{l}\text { Width of } \\
\text { boundary layer }\end{array}$ & $3 \times 10^{\wedge}-4$ (N.m. $-4(\mathrm{~N} . \mathrm{m})$. \\
\hline
\end{tabular}

4.1 The outcomes of CSMC with signum function in control law

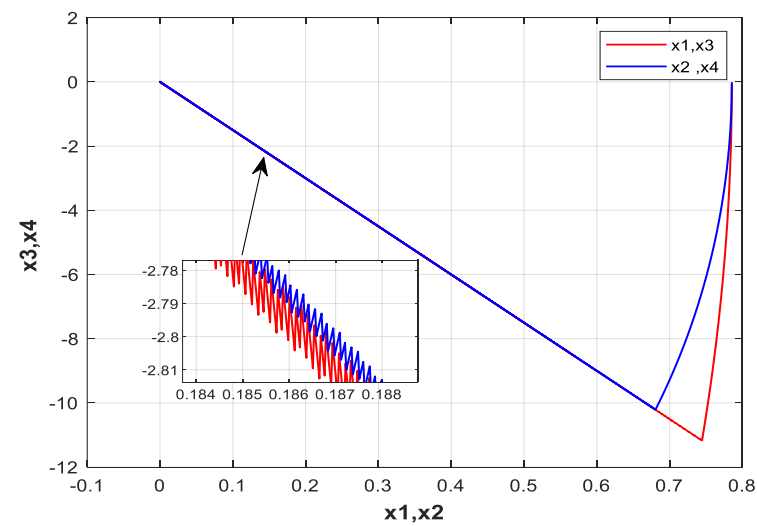

Figure (5): The Phase Plane Between x1 \& x2 Against x3 \& x4 Respectively

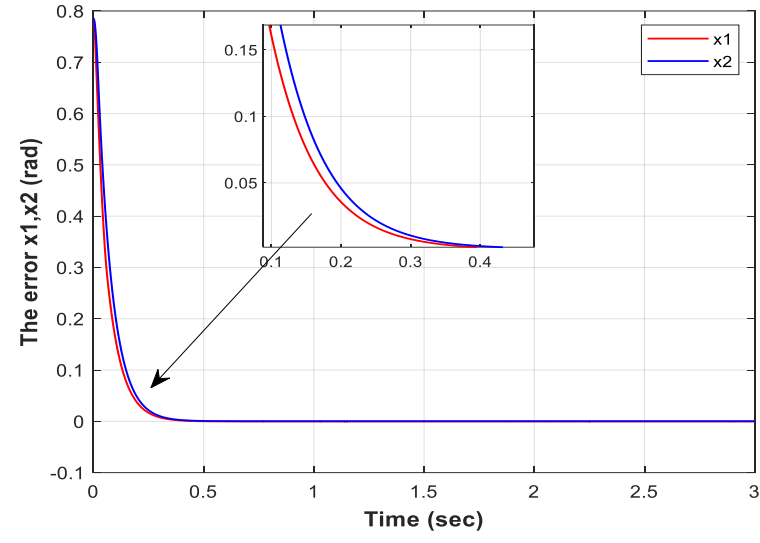

Figure (6): The Plot of Error x1\& x2 With Time.

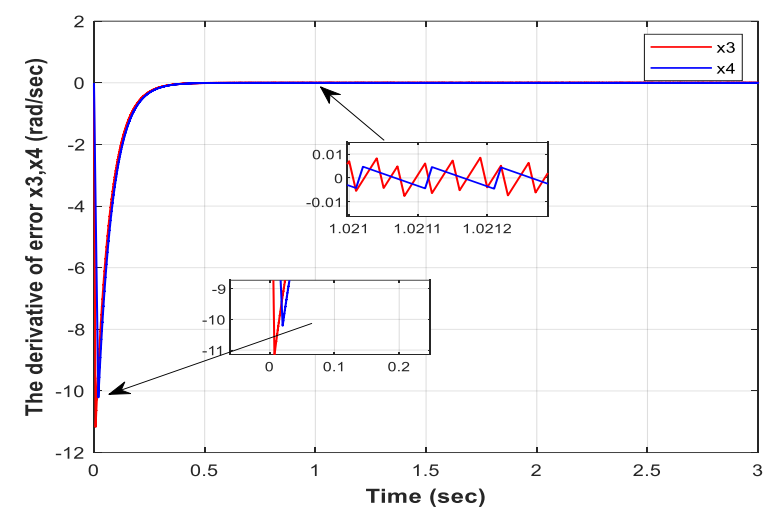

Figure (7): The Plot of $x 3 \& \times 4$ With Time.

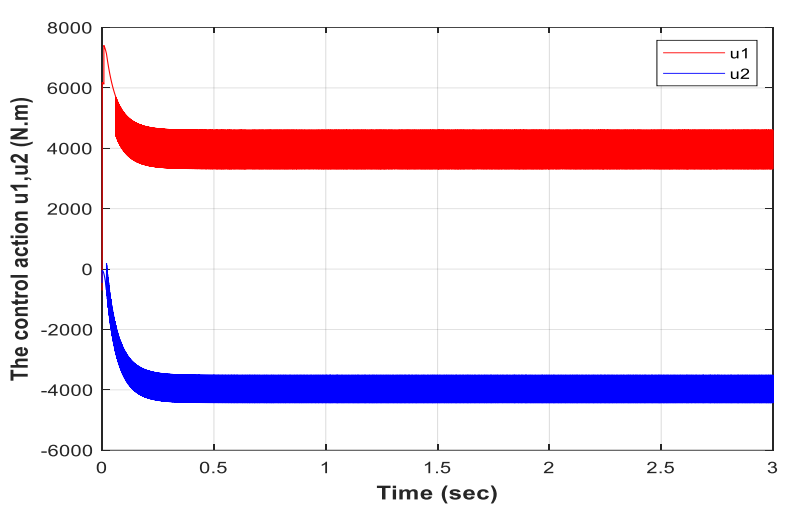

Figure (8): The Control Action u1 \& u2 With Time.

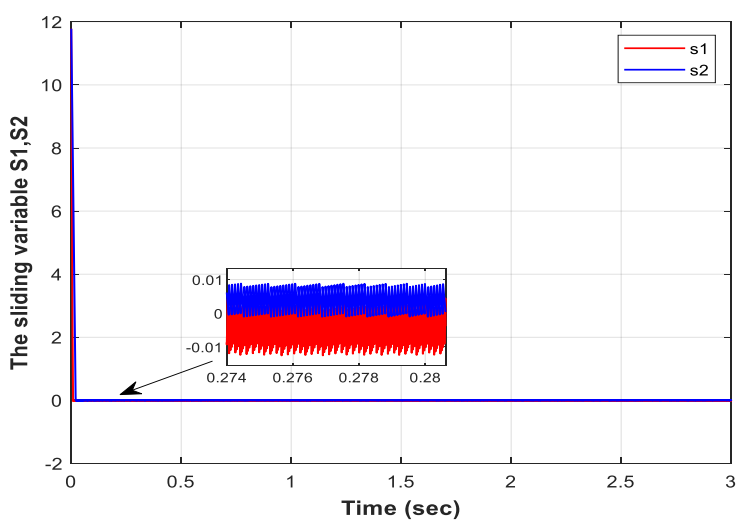

Figure (9): The (SV) s1 \& s2 with Time. 


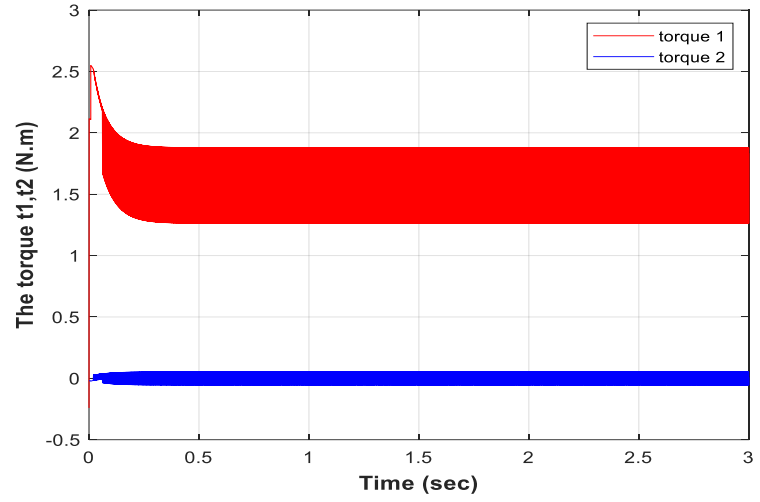

Figure (10): The Torque $\tau_{1} \& \tau_{2}$ with Time.

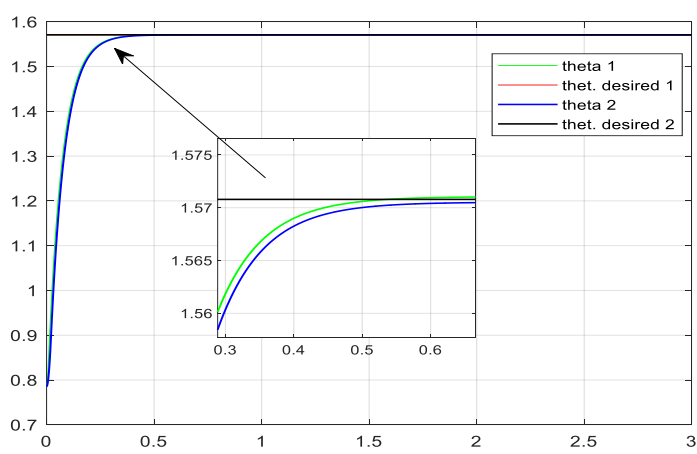

Figure (11): The Tracking Between Theta 1, Theta 2 And The Desired Theta 1, Theta 2 With Time.

4.2 The outcomes of CSMC with saturation function in control law

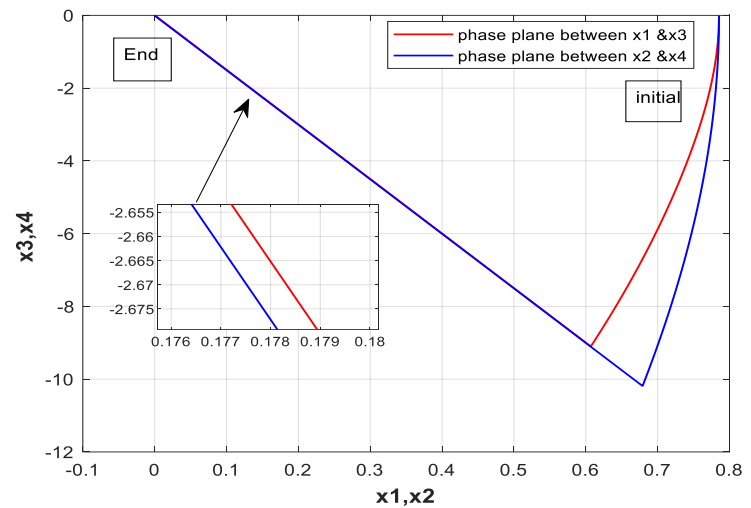

Figure (12): The Phase Plane Between $x 1 \& x 2$ Against $\mathrm{x} 3 \& \mathrm{x} 4$.

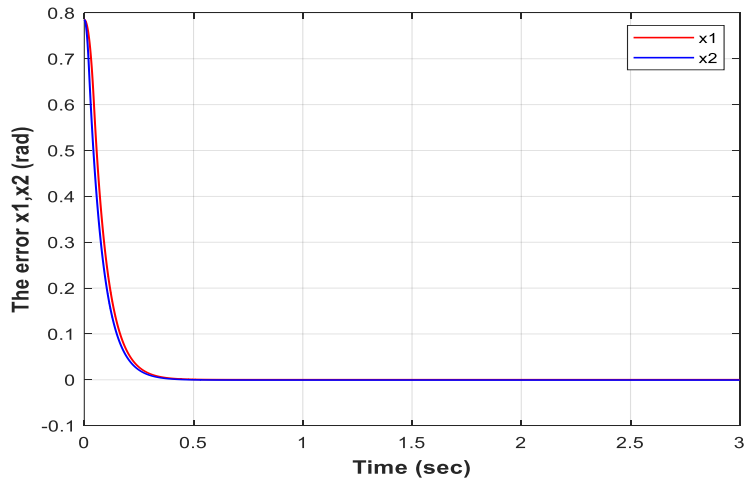

Figure (13): The Error x1(rad.) \& x2(rad.) With Time.

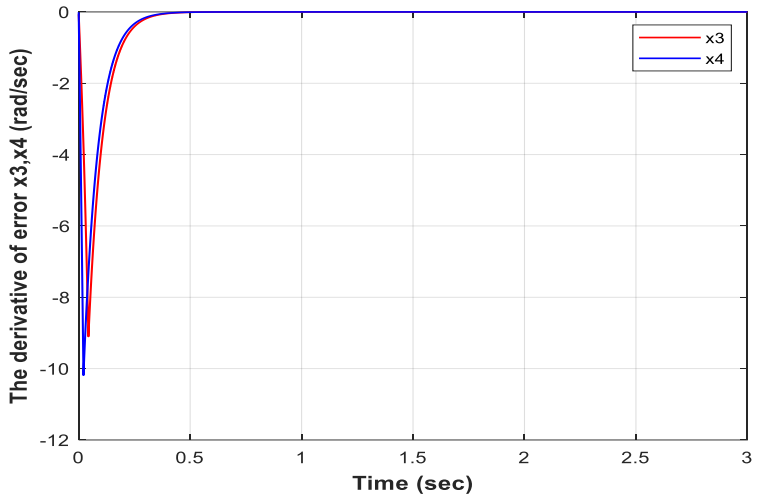

Figure (14): The Plot of $x 3 \& x 4$ with Time.

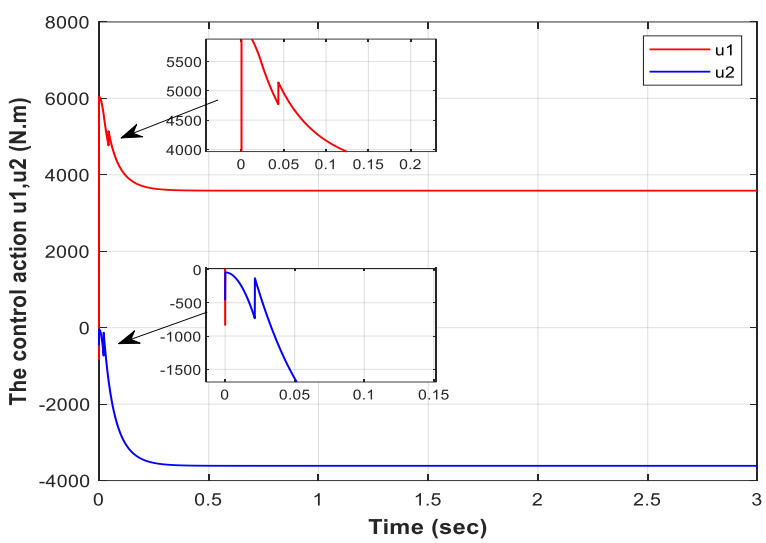

Figure (15): The Control Action u1 \&u2 With Time.

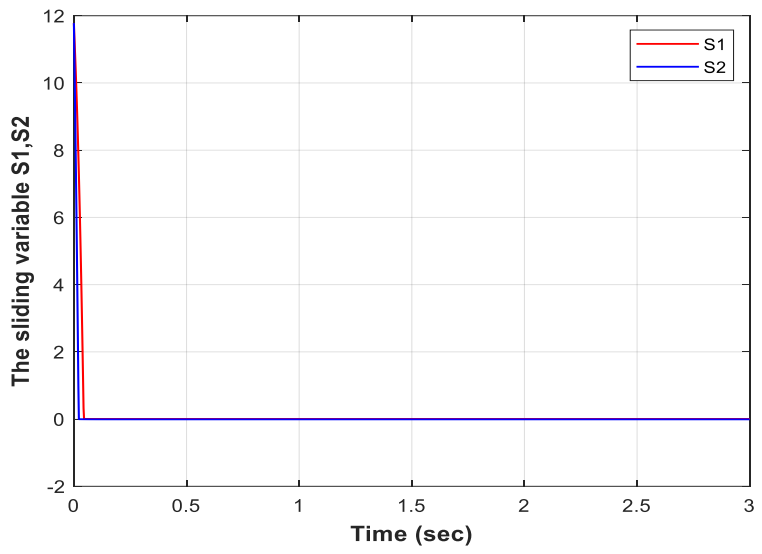

Figure (16): The (SV) S1 \& S2 with Time.

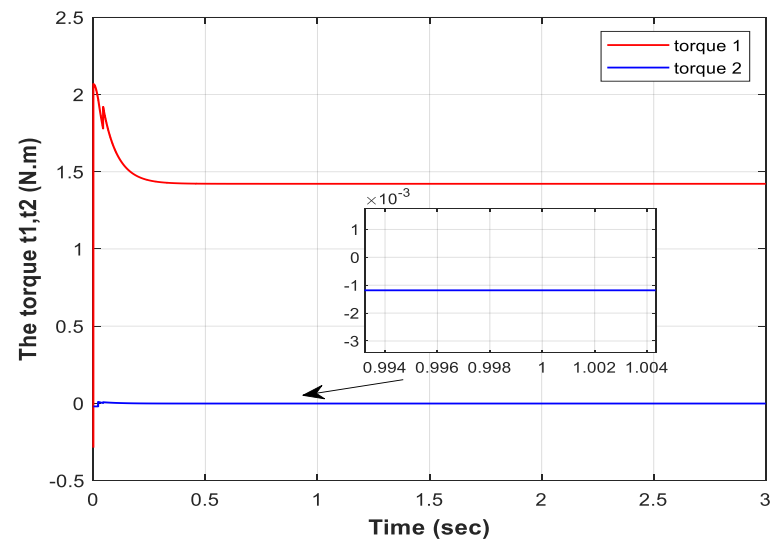

Figure (17): The Torque $\tau_{1} \& \tau_{2}$ with Time. 


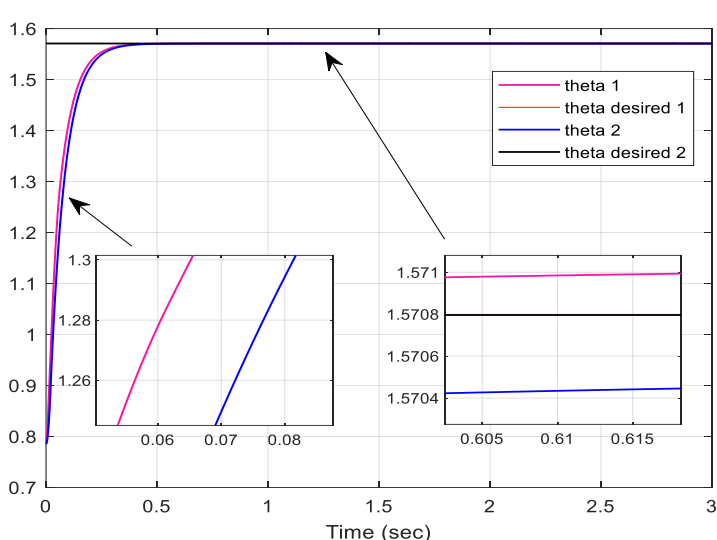

Figure (18): The Tracking Between Theta and Theta Desired with Time.

4.3 The outcomes of designing (ISMC) with sign function.

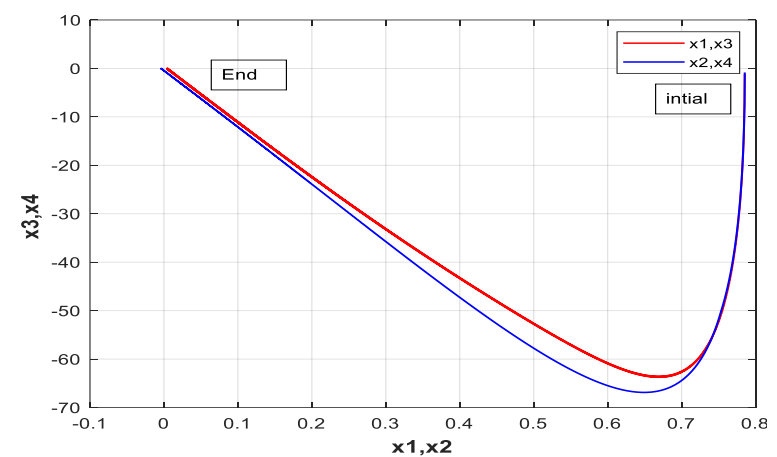

Figure (19): The Phase Plane Between x1 \&x2 Vs x3 $\& x 4$.

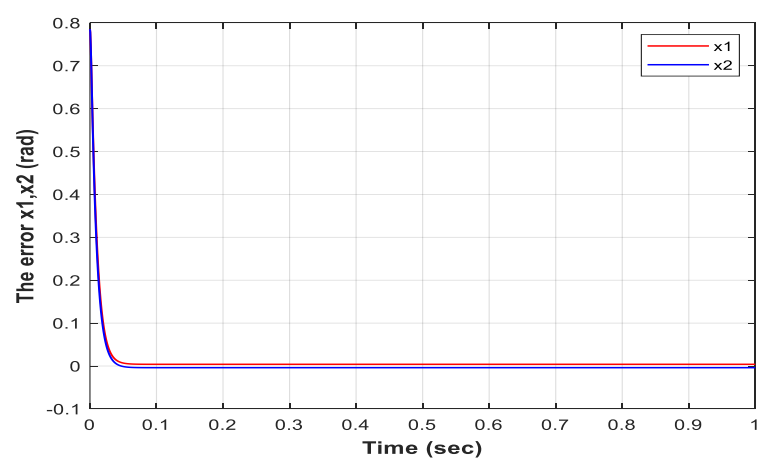

Figure (20): The Error x1 \& x2 with Time.

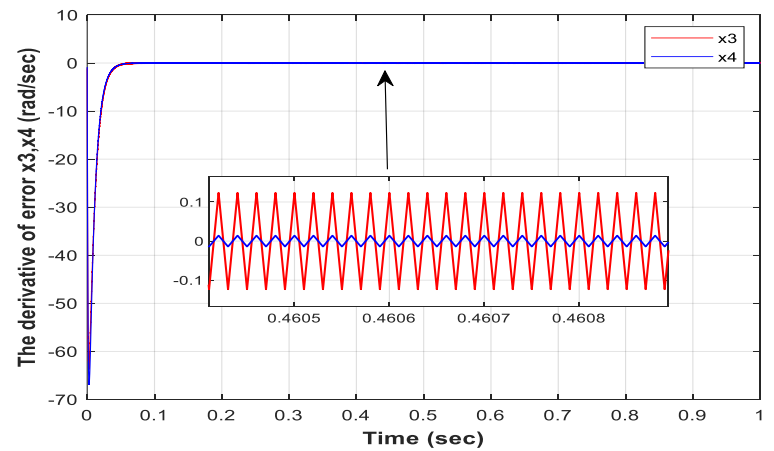

Figure (21): The Derivative of Error $\mathrm{x} 3$ \& $\mathrm{x} 4$ with

Time.

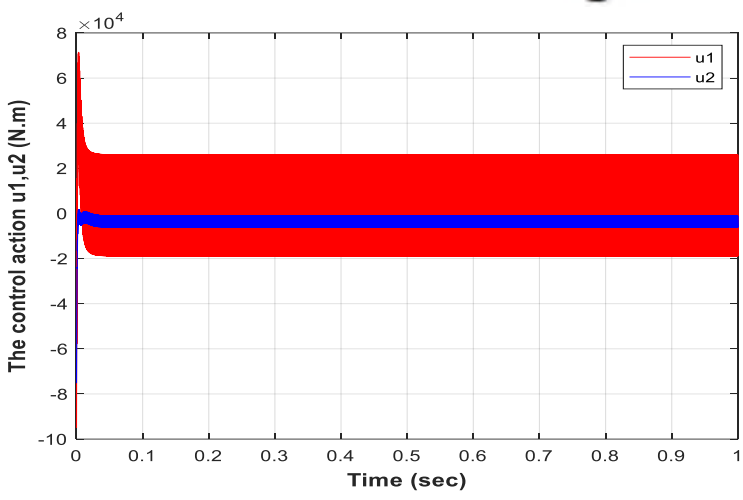

Figure (22): The Control Action u1 \& u2 With Time.

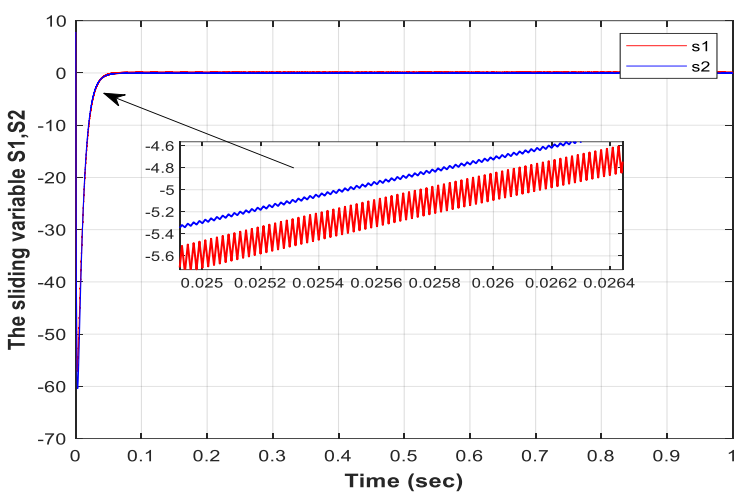

Figure (23): s1 \& s2 with time.

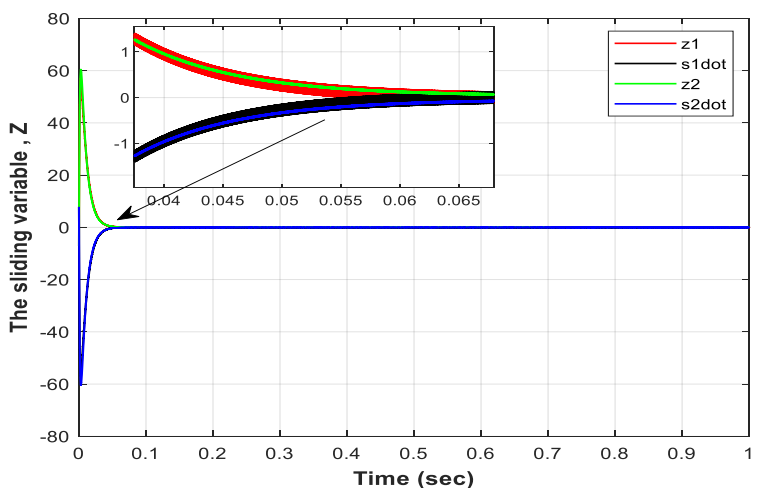

Figure (24): Sliding Variable \& Integral Term of 2Link Vs Time.

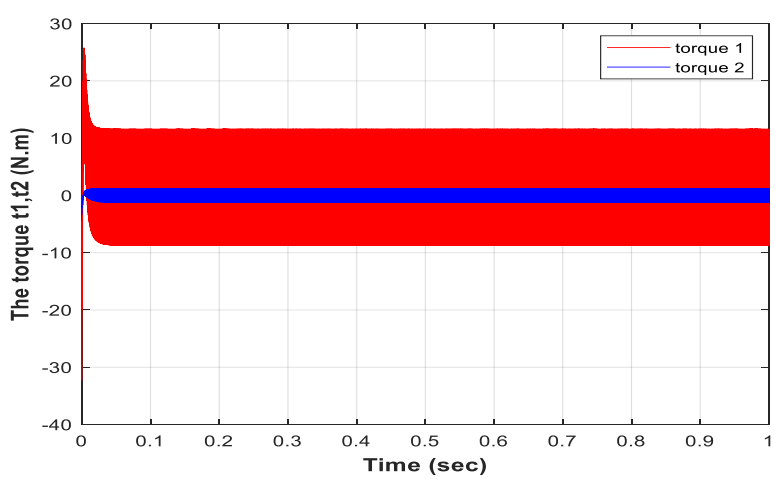

Figure (25): The Torque $\tau_{1} \& \tau_{2}$ with Time. 


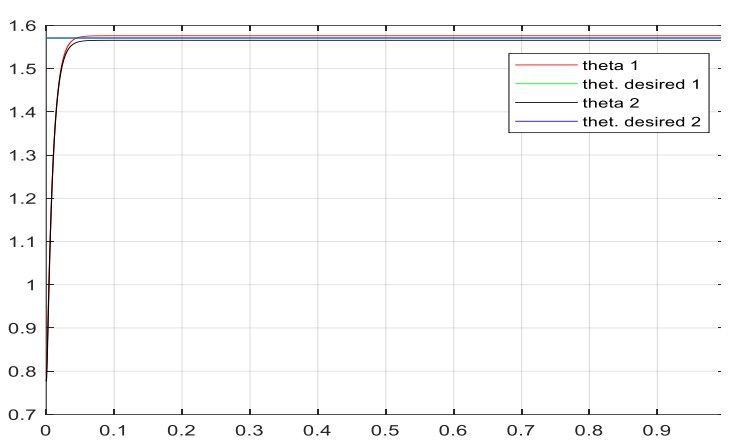

Figure (26): The Tracking Between Theta and Theta Desired With Time.

4.4The outcomes of designing (ISMC) with saturation function

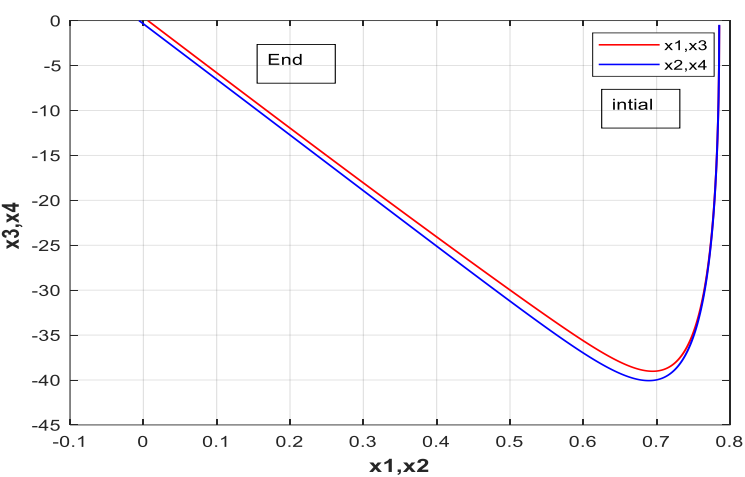

Figure (27): Phase-Plane Between x1\&x2 Vs x3 \&x4

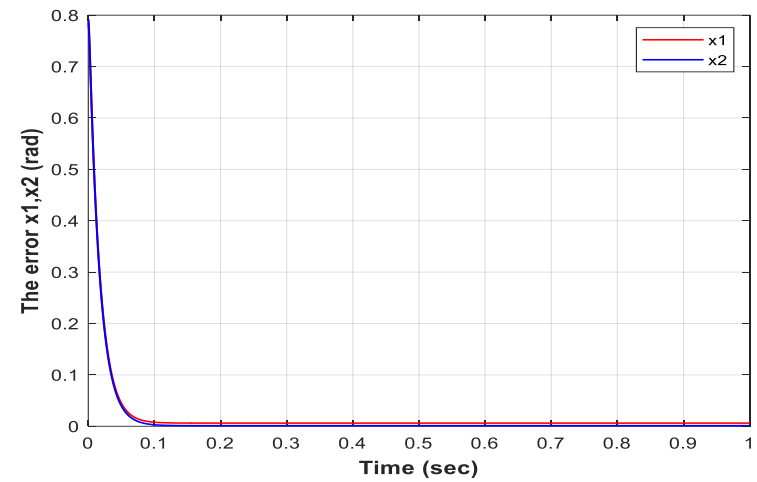

Figure (28): Error x1 \& x2 with Time.

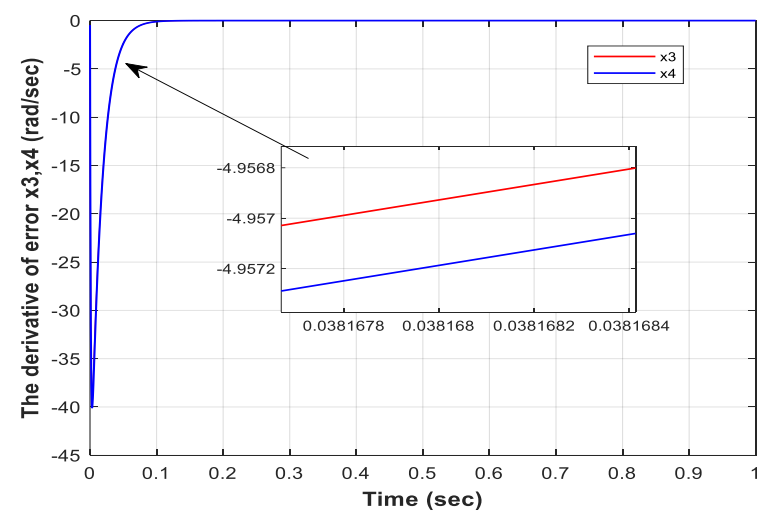

Figure (29): The Derivative of Error $\mathrm{x} 3 \& \mathrm{x} 4$ With Time.

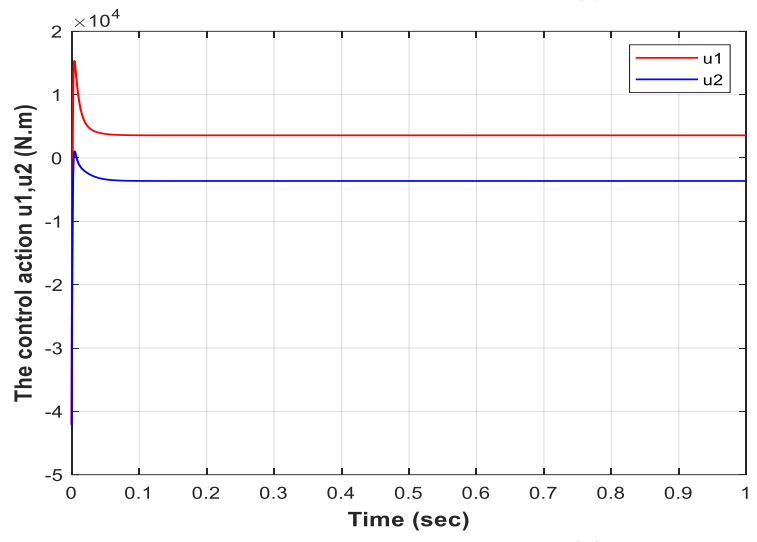

Figure (30): Control Action u1 \& u2 With Time.

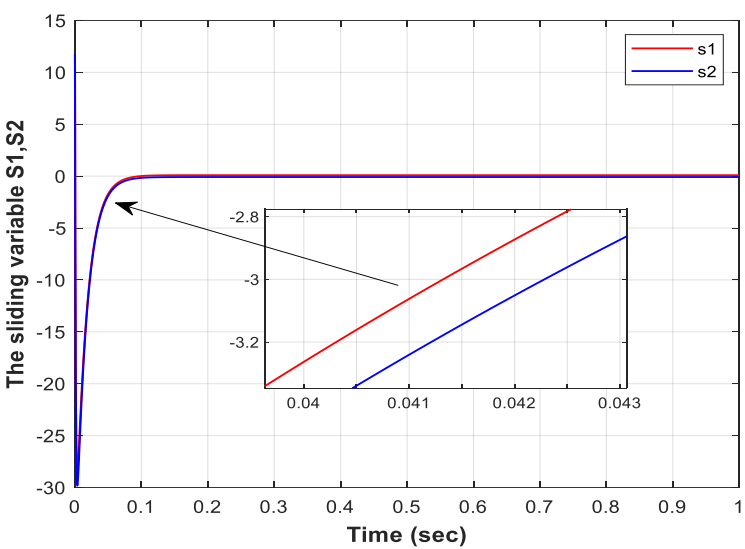

Figure (31): S1 \& S2 with Time.

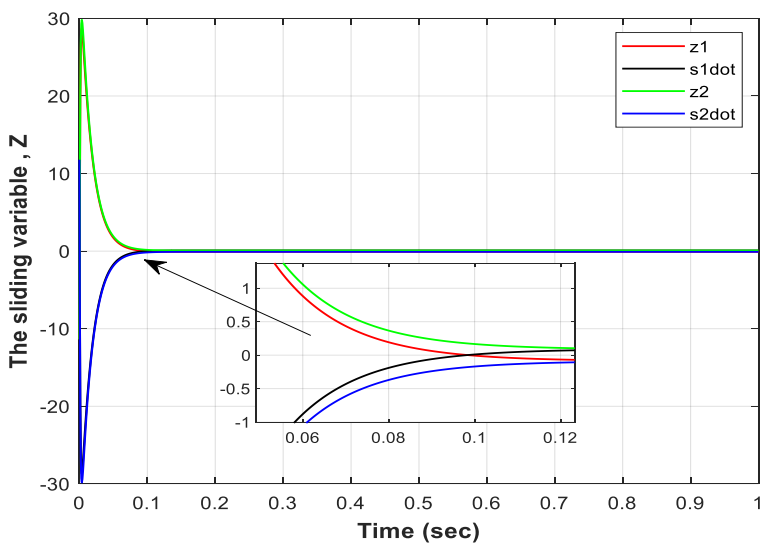

Figure (32): Integral Term \& Sliding Variable of 2 Link with Time.

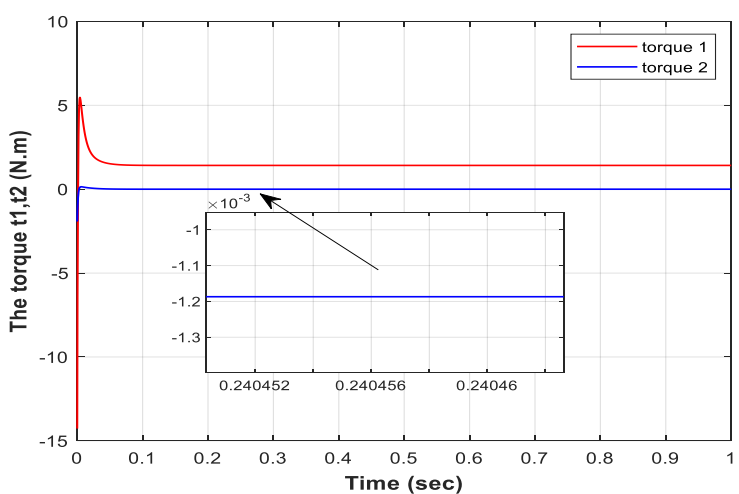

Figure (33): The Torque $\tau_{1} \& \tau_{2}$ with Time. 


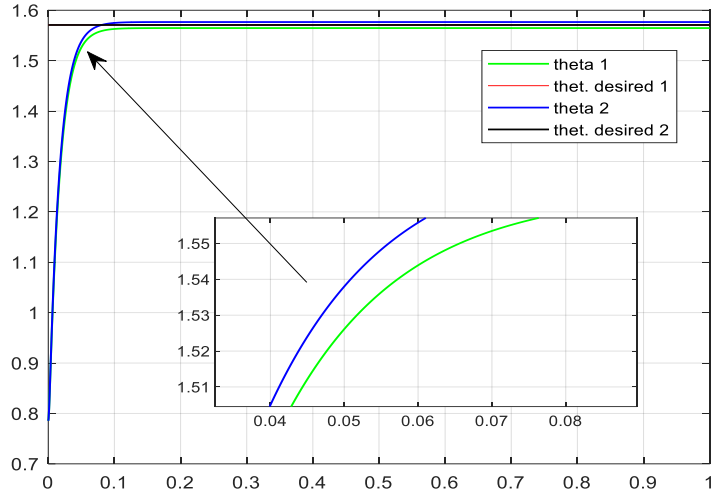

Figure (34): The Tracking Between Theta And Theta Desired With Time.

\section{Discussion}

In this paper, SMC and ISMC have been employing to control the position, velocity and tracking the desired position for the 2 link Robot system. The outcome of SMC and ISMC has consisted of this work to offer the characteristics of each controller with the existence of the outer disturbances and variables uncertainty. both controllers own the ability to create the system asymptotically stable which is subjected to the parameters uncertainty and external disturbance when the error ( $\mathrm{x} 1$ and $\mathrm{x} 2$ ) as illustrated in Fig. 6, Fig.13, Fig.20, Fig.28 and the derivative of error ( $\mathrm{x} 3$ and $\mathrm{x} 4$ ) as illustrated in Fig. 7, Fig.14, Fig.21, and Fig.29 approaching approximately to zero.

CSMC and ISMC are facing the problem of the chattering in the control action $\left(\mathrm{u}_{1}\right.$ and $\mathrm{u}_{2}$ ) in Fig.8 and Fig.22, torque action ( $\tau_{1}$ and $\left.\tau_{2}\right)$ Fig.10 and Fig.25 and sliding variable ( $\mathrm{s}_{1}$ and $\mathrm{s}_{2}$ ) Fig. 9 and Fig.23 because of the impact of signum function in the control law. The chattering problem is solved by utilizing the saturation function in the control law to attenuate the zigzag motion in $\mathrm{u}, \tau$ and $\mathrm{s}$ as shown in Fig.15 and Fig.30, Fig.17 and Fig.33 , Fig.16 and Fig.31 respectively.

When employing the sign function, the state trajectories in the CSMC and ISMC reache the switching surface perpendicularly as shown in Fig.5, Fig. 19 this way of movement leads to a chattering phenomenon.

while in utilizing the boundary layer (sat function) the state trajectories are hitting the sliding surface in the arc model as in Fig. 12 and Fig. 27 which lead to minimize the chattering.

The outcomes present that the actions of the external disturbance and the parameters uncertainty of the dynamic system is eliminated by employing saturation function.

Each theta of two links is tracking the desired position as shown in Fig.11, Fig.18, Fig.26 and Fig.34.

For achieving the eq. (20) in designing ISMC, Fig.24 in case of sign (some chatter motion) and Fig.32 in case of saturation (smooth motion) have clarified this equation. The integral term (z1 and z2) was updated to keep the sliding variable (s1 and s2) on the zero.

\section{Conclusion}

The most substantial enhancement of using ISMC is the decreasing of the settling time and steady-state error response of reaction compared with the CSMC as shown in Table 2.

The ISMC includes two sections, the first section is nominal control which is utilized for controlling the certain system. the second section is the discontinuous control that is employed to refuse the perturbation term (the term of perturbation contains the external disturbance and parameter uncertainty). The nominal part is not impacted by the perturbation term.

The outcomes present that CSMC and ISMC can be described as a powerful algorithm, for the reason that they can give a perfect response (good tracking for the desired position with minimum possible time and assurance the stability through reaching approximately zero in the slipping mode) although the existence of external disturbance and variables uncertainty.

From Table 2, settling time for ISMC is lesser about $75 \%$ than CSMC for each link with each case. The steady state error with (signum and saturation) function is lesser about $(77 \%$ and $73 \%$ and $88 \%$, 94\%) than CSMC for link1 and link2 respectively. So that we can be concluded that ISMC outperform CSMC according to the simulation results of the system.

Table (2): Performance of CSMC and ISMC with Disturbances and Uncertainty.

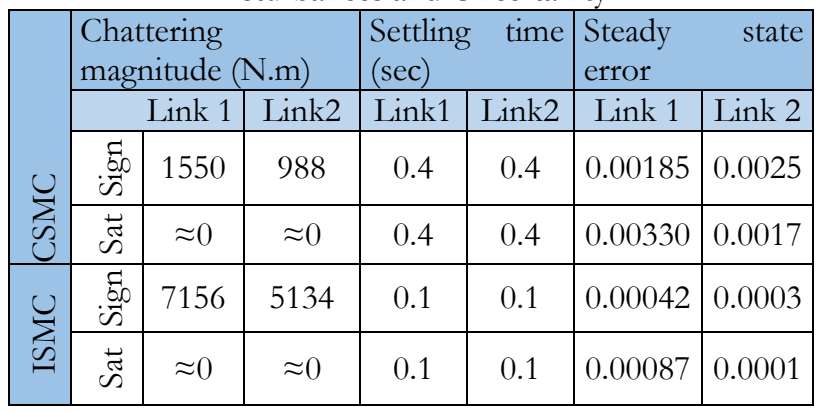

\section{References:}

[1] Z. Xiaoyu, "Integral sliding mode control for nonlinear systems with mismatched uncertainty based on quadratic sliding mode". The Journal of Engineering , no. 4, pp. 154-159, 2015.

[2] S. Laghrouchea, F. Plestanb, and A. Glumineaub," Higher order sliding mode control based on integral sliding mode", Automatica 43, pp. 531 - 537, 2007.

[3] A. K. Hamoudi, and N. O. Abdul Rahman, "Design an Integral Sliding Mode Controller for a Nonlinear System“, Al-Khwarizmi Engineering Journal, Department of Control and Systems Engineering/ University of Technology, vol. 13, no. 1, pp. 138-147, 2017.

[4] B. Punitkumar, and V. Kumar, "Trajectory tracking of linear inverted pendulum using integral sliding mode control", International Journal of Intelligent Systems and Applications, 2012. 
[5] N. O. Abdul Rahman, " Design of Sliding Mode Controllers For Linear and Nonlinear Systems ", M. Sc. Thesis, Control and Systems Engineering Department, University of Technology, Baghdad, Iraq, 2016.

[6] S.Mobayen, F. Tchier and L. Ragoub, "Design of an adaptive tracker for $\mathrm{n}$-link rigid robotic manipulators based on super-twisting global nonlinear sliding mode control", International Journal of Systems Science, vol.48, 2017.

[7] A. K. Hamoudi, and Sh. A. Hashim, "Design of second order sliding mode controller for a nonlinear system “, Engineering and Technology Journal, 2019.

[8] A. K. Hamoudi, "Design and Simulation of Sliding Mode Fuzzy Controller for Nonlinear System ", Journal of Engineering, College of Engineering, University of Baghdad, vol. 22, no. 3, 2016.

[9] Y. Pan, Ü. Özgüner, and O. Da gci, "Variable Structure Control of Electronic Throttle Valve", IEEE Transaction on Industrial Electronics, vol. 55, no. 11,2008.

[10] A. S. Badri, "Integral Sliding Mode Controller Design for Electronic Throttle Valve ", M. Sc. Thesis, Control and Systems Engineering Department, University of Technology, Baghdad, Iraq, 2014.

[11] Z. Yue, and S. Zhu, "Adaptive sliding mode control based on uncertainty and disturbance estimator." Mathematical Problems in Engineering, 2014.

[12] M. M. Salih, " Adaptive Sliding Mode Controllers Design with Application to Mechanical Systems", M. Sc. Thesis, Control and Systems Engineering Department, University of Technology, Baghdad, Iraq, 2016.

[13] V. Utkin, J. Guldner, and J.Shi, Sliding mode control in electro-mechanical systems. CRC Press, 2009

[14] J.X. Xu, Z.Q. Guo, and T. H.Lee, "Design and implementation of integral sliding-mode control on an underactuated two-wheeled mobile robot", IEEE Transactions on industrial electronics vol.61, no. 7 , pp.3671-3681, 2013.

[15] A. Sareena, and P. Rikesh," Application of PID Controller and Nonlinear Sliding Mode Control on Two Link Robotic Manipulator”, vol. 8 ,no. 5, pp. 504-508,2019.

[16] Y.A .Shafeek, "Robust Modified Adaptive Fuzzy Sliding Mode Control For Nonlinear Systems”, M.Sc thesis, 2007

[17] M.T.Do, "Sliding Mode Learning Control and its Applications", Ph.D. Thesis, Swinburne University of Technology Melbourne, Australia,2014.

[18] Young, Utkin and "Umit "Ozg"uner," A Control Engineer's Guide to Sliding Mode Control", IEEE, vol. 7 , no. 3, pp. 328-342,1999.

[19] V. Utkin and J. Shi," Integral Sliding Mode in Systems Operating under Uncertainty Conditions", Conference on Decision and Control, IEEE, 1996.

[20] R.N. Jazar," Theory of Applied Robotics", springer, Second Edition,2010.

[21] Sh. A. Hashim, " Design of Second Order Sliding Mode Control Algorithm for A Nonlinear System", M Sc. Thesis, Control and Systems Engineering Department, University of Technology,
Baghdad, Iraq, 2019.

[22] H. M. Abdelghaffar, M. Elouni, Y. Bichiou, and H. A. Rakha, "Development of a Connected Vehicle Dynamic Freeway Sliding Mode Variable Speed Controller", IEEE Access,2020.

[23] A. Pilloni, M. Franceschelli, A. Pisano, and E. Usai, "Sliding mode based robustification of consensus and distributed optimization control protocols", IEEE Transactions On Automatic Control, February, 2020.

[24] A. Souza, D. Efimov, A. Polyakov, and J. Gouzé, "Robust Control of a Competitive Environment in the Chemostat using Discontinuous Control Laws", IEEE Conference on Decision and Control, Dec., 2019 .

[25] B. Deng, K. Shao, and H. Zhao," Adaptive Second Order Recursive Terminal Sliding Mode Control for a Four-Wheel Independent Steer-by-Wire System", IEEE Access, Vol. 8, 2020.

[26] S. Zhuk, A. Polyakov and O. Nakonechnyi, "Note on Minimax Sliding Mode Control Design for Linear Systems", IEEE Transactions on Automatic Control, Institute of Electrical and Electronics Engineers, 2016. 